\title{
Activation energy determination for linear heating experiments: deviations due to neglecting the low temperature end of the temperature integral
}

\section{M.J. Starink}

Materials Research Group, School of Engineering Sciences, University of Southampton, Southampton S017 1BJ, UK

Keywords: thermally activated reaction; activation energy; thermal analysis; linear heating; curing

Submitted: 28 July 2005 / Accepted: 18 January 2006

\begin{abstract}
Model-free isoconversion methods which use approximations of the temperature integral are generally reliable methods for the calculation of activation energies of thermally activated reactions studied during linear heating. These methods generally neglect the temperature integral at the start of the linear heating, $I\left(T_{o}\right)$. An analytical equation is derived which describes the deviations introduced by this approximation. It is shown that for most reactions encountered this assumption does not have a significant influence on the accuracy of the method. However, in cases where $T_{o}$ is within about 50 to $70 \mathrm{~K}$ of the reaction stage to be investigated and activation energies are relatively low, significant deviations are introduced. It is shown that some of the published thermal analysis work on activation energy analysis of reactions occurring at relatively low temperatures is affected by these deviations. Examples are specific cases of dehydration reactions, cure reactions and cluster formation in $\mathrm{Al}$ alloys.
\end{abstract}

\section{Introduction}

A general objective of the analysis and prediction of thermally activated reactions is the derivation of a complete description of the progress of a reaction that is valid for any thermal treatment, be it isothermal, by linear heating or any other non-isothermal treatment $[1,2,3]$. As any given reaction might progress through a range of mechanisms and intermediate stages, all of which can have a different temperature-dependency, this aim can be difficult to achieve. Hence, many researchers make the simplifying assumption that the transformation rate during a reaction is the product of two functions, one depending solely on the temperature, $T$, and the other depending solely on the fraction transformed, $\alpha[4,5]$ : $\frac{d \alpha}{d t}=f(\alpha) k(T)$

The temperature dependent function is generally assumed to follow an Arrhenius type dependency [6,7].

$k=k_{o} \exp \left(-\frac{E}{R T}\right)$

Thus, to describe the progress of the reaction at all temperatures and for all temperature-time programmes within these assumptions, the function $f(\alpha)$, and the constants $k_{o}$ and $E$ need to be determined. For nonisothermal experiments, the reaction rate at all times depends on both $f(\alpha)$ and $k(T)$, and the determination of $f(\alpha), k_{o}$ and $E$ (the so-called kinetic triplet) is an interlinked problem (see e.g. [8]). A deviation in the determination of any of the three will cause a deviation in the other parameters of the triplet. Reliable analysis methods generally start by deriving the activation energy using a model-free analysis method [9], i.e. a method which makes no presumptions of $f(\alpha)$.

It has been shown that for analysis of linear heating experiments (heating at constant rate), highly accurate and reliable activation energy analysis methods can be obtained by applying accurate approximations of the temperature integral [10]. This derivation can be formulated as follows. Eq. (2) is inserted in Eq. (1) and this is integrated by separation of variables [10]:

$\int_{T o}^{T_{f}} \frac{d \alpha}{f(\alpha)}=\frac{k_{o}}{\beta} \int_{T_{o}}^{T_{f}} \exp \left(-\frac{E}{R T}\right) d T=\frac{k_{o}}{\beta}\left[\int_{0}^{T_{f}} \exp \left(-\frac{E}{R T}\right) d T-\int_{0}^{T_{o}} \exp \left(-\frac{E}{R T}\right) d T\right]$

where $T_{f}$ is the temperature at an equivalent (fixed) state of transformation, $T_{o}$ is the start temperature of the linear heating experiment, and $\beta$ is the heating rate. The integrals 
on the right hand side are generally termed temperature integrals (or 'Arrhenius integral'). We can write Eq. 3 as:

$$
\int_{T_{o}}^{T_{f}} \frac{d \alpha}{f(\alpha)}=\frac{k_{o}}{\beta}\left[I\left(T_{f}\right)-I\left(T_{o}\right)\right]
$$

where $I\left(T_{o}\right), I\left(T_{f}\right)$ are the temperature integrals on the right hand side of Eq. 3.

The derivation proceeds by noting that of the last two terms, one is much smaller than the other

$$
\int_{0}^{T o} \exp \left(-\frac{E}{R T}\right) d T<<\int_{0}^{T_{f}} \exp \left(-\frac{E}{R T}\right) d T
$$

or $I\left(T_{o}\right)<<I\left(T_{f}\right)$. And hence $I\left(T_{o}\right)$, the smaller term in Eq. 4 , is neglected. Thus it follows that:

$$
\int_{T o}^{T_{f}} \frac{d \alpha}{f(\alpha)} \cong \frac{k_{o}}{\beta}\left[\int_{0}^{T_{f}} \exp \left(-\frac{E}{R T}\right) d T\right]
$$

Through applying a suitable approximation for the temperature integral on the right of the latter equation a range of well-known and lesser known isoconversion methods for activation energy analysis can be derived [10]. These methods include the Kissinger method [11], the Kissinger-Akahira-Sunose (KAS) method [12,13] (also termed the generalised Kissinger method), the Flynn-WallOzawa (FWO) method [14,15], a method described by Vyazovkin and co-workers [16,17] and 3 highly accurate methods developed by the present author [10,18,19]. All of these methods involve the plotting of $1 / T_{f}$ vs. a logarithmic function which depends on the heating rate and often the temperature and all of these methods neglect the last integral term in Eq. 3 ( $I\left(T_{o}\right)$ in Eq. 4). The general equation is:

$\ln \frac{\beta}{T_{f}{ }^{\kappa}}=-A \frac{E}{R T_{f}}+C$

where $\kappa$ is a constant depending on the approximation of the temperature integral employed [1], and $A$ and $C$ are constants. For the above mentioned methods $\kappa$ equals 0 (FWO method), 2 (KAS method) and 1.9 to 1.95 for the methods by Starink [10]. Whilst all of these works [9-18] (and a vast range of other works) imply that the approximation involved in neglecting $I\left(T_{o}\right)$ is appropriate, it appears that the actual influence of this approximation on the analysed activation energy values has never been quantitatively determined. The aim of the present short paper is to investigate the accuracy of this approximation.

\section{Analysis}

In derivation of isoconversion methods it is generally assumed that $I\left(T_{o}\right)<<I\left(T_{f}\right)$ and $I\left(T_{o}\right)$ is subsequently neglected. However, it can be shown that in a limited number of cases this is not justified, and in this section we will derive an expression for the deviations in measured $E$ introduced as a consequence of neglecting $I\left(T_{o}\right)$.

We will specifically analyse the case where two experiments at two different heating rates, $\beta_{1}, \beta_{2}$, are conducted. If a larger range of experiments are performed the analysis should be valid in good approximations provided $\beta_{l}, \beta_{2}$, are taken as the upper and lower heating rate considered. From Eq. 4 follows that if a certain fixed state of the reaction is attained at the two different heating rates:

$\frac{k_{o}}{\beta_{1}}\left[I\left(T_{f 1}\right)-I\left(T_{o}\right)\right]=\frac{k_{o}}{\beta_{2}}\left[I\left(T_{f 2}\right)-I\left(T_{o}\right)\right]$

Where $T_{f 1}$ is the temperature at which the fixed state is reached at heating rate $\beta_{1}$ and $T_{f 2}$ is the temperature at which the same fixed state is reached at heating rate $\beta_{2}$. From the latter equation follows:

$\frac{\beta_{2}}{\beta_{1}}=\frac{I\left(T_{f 2}\right)-I\left(T_{o}\right)}{I\left(T_{f 1}\right)-I\left(T_{o}\right)}$

and

$\frac{\beta_{2}}{\beta_{1}}=\frac{I\left(T_{f 2}\right)}{I\left(T_{f 1}\right)} \frac{1-I\left(T_{o}\right) / I\left(T_{f 2}\right)}{1-I\left(T_{o}\right) / I\left(T_{f 1}\right)}$

For further evaluation of the temperature integrals, we will employ Doyle's approximation:

$\int_{0}^{T} \exp (-E / R T) d T \approx \frac{E}{R}\left(0.00484 e^{-1.0516 \frac{E}{R T}}\right)$

(The accuracy of the latter equation has limitations $[7,10]$. However, its relative simplicity is here exploited to obtain mathematically tractable solutions. Small inaccuracies introduced are in this case considered to be acceptable.) From the latter equation, we can obtain an expression for the ratio of two temperature integrals: 
$\ln \frac{I\left(T_{f 2}\right)}{I\left(T_{f 1}\right)} \approx 1.0516 \frac{E}{R} \times\left[1 / T_{f 2}-1 / T_{f 1}\right]$

Combining the latter equation with Eq. 10 provides:

$\ln \frac{\beta_{2}}{\beta_{1}}-\ln \frac{1-I\left(T_{o}\right) / I\left(T_{f 2}\right)}{1-I\left(T_{o}\right) / I\left(T_{f 1}\right)}=\ln \frac{I\left(T_{f 2}\right)}{I\left(T_{f 1}\right)} \cong 1.0516 \frac{E}{R} \times\left[1 / T_{f 2}-1 / T_{f 1}\right]$

The aim of this paper is to investigate the consequences of neglecting $I\left(T_{o}\right)$, using $I\left(T_{o}\right)<<I\left(T_{f 1}\right), I\left(T_{f 2}\right)$. If we were to do this the latter equation would simplify to:

$\ln \frac{\beta_{2}}{\beta_{1}}=\ln \frac{I\left(T_{f 2}\right)}{I\left(T_{f 1}\right)} \cong 1.0516 \frac{E_{u}}{R} \times\left[1 / T_{f 2}-1 / T_{f 1}\right]$

Where $E_{u}$ stands for the activation energy obtained from an analysis in which $I\left(T_{o}\right)$ is neglected. (The latter equation is essentially the Flynn-Wall-Ozawa method [14,15].) Taking the difference of the latter two equations provides:

$\ln \frac{1-I\left(T_{o}\right) / I\left(T_{f 2}\right)}{1-I\left(T_{o}\right) / I\left(T_{f 1}\right)} \cong 1.0516 \frac{\Delta E}{R} \times\left[1 / T_{f 2}-1 / T_{f 1}\right]$

Where $\Delta E=E_{u}-E$, the error in $E$ introduced by neglecting $I\left(T_{o}\right)$. As long as $I\left(T_{o}\right)$ is small compared to $I\left(T_{f 1}\right)$ and $I\left(T_{f 2}\right)$ it is justified to make a first order approximation:

$$
\begin{aligned}
\ln \frac{1-I\left(T_{o}\right) / I\left(T_{f 2}\right)}{1-I\left(T_{o}\right) / I\left(T_{f 1}\right)} \cong \ln \left[1+I\left(T_{o}\right) / I\left(T_{f 1}\right)-I\left(T_{o}\right) / I\left(T_{f 2}\right)\right] \\
\cong I\left(T_{o}\right) / I\left(T_{f 1}\right)-I\left(T_{o}\right) / I\left(T_{f 2}\right) \\
\cong \exp \left(-1.0516 \frac{E}{R}\left[\frac{1}{T_{f 2}}-\frac{1}{T_{o}}\right]\right)-\exp \left(-1.0516 \frac{E}{R}\left[\frac{1}{T_{f 1}}-\frac{1}{T_{o}}\right]\right)
\end{aligned}
$$

Where the last step of the above derivation is achieved by employing Eq. 12.

Thus we obtain:

$$
\frac{\Delta E}{R} \cong \frac{\exp \left(-1.0516 \frac{E}{R}\left[\frac{1}{T_{f 2}}-\frac{1}{T_{o}}\right]\right)-\exp \left(-1.0516 \frac{E}{R}\left[\frac{1}{T_{f 1}}-\frac{1}{T_{o}}\right]\right)}{1.0516\left(\frac{1}{T_{f 2}}-\frac{1}{T_{f 1}}\right)}
$$

From the latter equation we can see that the deviation $\Delta E$ introduced by neglecting $I\left(T_{o}\right)$ can be calculated in a direct and straightforward equation. $\Delta E$ is a function of $T_{o}, T_{f 1}, T_{f 2}$ and $E$, where $T_{f 1}$ and $T_{f 2}$ are a function of $\beta_{1}$ and $\beta_{2}$, respectively.

The temperature differential $\left(T_{f 2}-T_{f l}\right)$ depends on $E$, $\beta_{1}$ and $\beta_{2}$, and in practical cases $\left(T_{f 2}-T_{f l}\right)$ is between about 10 and $50 \mathrm{~K}$. Analysis of Eq. 17 will show that under these conditions $E, T_{o}$ and the difference between $T_{f l}$ and $T_{o}$ are the dominant parameters determining $\Delta E$. Thus, unless otherwise noted, we will generally set $\left(T_{f 2}-T_{f 1}\right)=30 \mathrm{~K}$, which will limit the number of independent variables that need to be considered.

\section{$3 \quad$ Experimental}

Most of the data presented below is taken from recent literature, and in addition an Al-1.21at $\% \mathrm{Cu}-1.19 \mathrm{at} \% \mathrm{Mg}$ $0.20 \% \mathrm{Mn}$ alloy has been studied. Details on production route for this alloy are given in Ref. [20]. After solution treatment at $768 \mathrm{~K}$, water quenching and stretching by $2.5 \%$, the alloy was left at room temperature for a few months before further ageing at $423 \mathrm{~K}$. Differential Scanning Calorimetry (DSC) experiments were conducted using a Perkin-Elmer Pyris 1 in nitrogen atmosphere at a constant heating rate of $10 \mathrm{~K} / \mathrm{min}$, using disc-shaped DSC samples with a thickness of about 0.9 $\mathrm{mm}$ and diameter $5 \mathrm{~mm}$. All runs were corrected by subtracting the baseline of the DSC, which was obtained from a run with an empty pan as reference. Further baseline correction procedures are outlined in Ref. [1].

\section{$4 \quad$ Evaluation and Application}

\subsection{General assessment of consequences of neglecting $I\left(T_{o}\right)$.}

The analysis presented above shows that neglecting $I\left(T_{o}\right)$ causes the activation energy measured by the isoconversion method to be increased. In evaluating the potential importance of this deviation we should consider that other sources of mathematic approximation error are typically in the order of 0.1 to $0.5 \%$, for the more accurate methods $[1,10]$. But more important sources of measurement error are sample variability and various sources of experimental noise, which combine to produce plots of $\ln \left(\beta / T_{f}{ }^{\kappa}\right)$ vs. $1 / T_{f}$ that do not have the predicted perfect straight line correlation, resulting in an experimental error. These sources of error 
depend on many factors and can vary wildly, to produce potential errors typically from 0.2 to $5 \%$. In this work we will consider $0.5 \%$ as a practical limit below which mathematical errors are mostly irrelevant, but it is noted that even larger mathematical errors can become irrelevant if sample variability and various sources of experimental noise combine to produce large errors.

Evaluation of Eq. 17 for literature reports of determinations of activation energies for linear heating data using an isoconversion method, reveals that $\Delta E / E$ caused by neglecting $I\left(T_{o}\right)$ is negligible for the vast majority reported studies. (About 500 papers were scanned and only about $1 \%$ reported on reactions with a combination of $T_{o}, T_{f 1}, T_{f 2}$ and $E$ that could introduce a possibly significant deviation.) For instance, for reactions with $E>70 \mathrm{~kJ} / \mathrm{mol}$ and $T_{f l}>375 \mathrm{~K}, \Delta E / E$ is smaller than $0.5 \%$ provided $T_{f 1}-T_{o}>65 \mathrm{~K}$, i.e. if the linear heating is started at least $65 \mathrm{~K}$ before the reaction stage to be studied, $\Delta E / E$ will be negligible under realistic experimental conditions. (Other factors such as measurement noise, sample variability and baseline variations, will generally combine to introduce more significant errors $[1,10]$.) And if $E>100 \mathrm{~kJ} / \mathrm{mol}, T_{f 1}-T_{o}$ needs to be larger than $50 \mathrm{~K}$ to achieve $\Delta E / E<0.005$.

Elsewhere [10] it was shown that the approximation of the temperature integral $I\left(T_{f}\right)$ also causes a deviation in the activation energy. The latter deviation can be minimised by choosing an accurate approximation, which leads to one of the more accurate isoconversion methods, and deviations due to approximation of the temperature integral can be limited to less than $0.5 \%$. From the present analysis combined with the analysis in Ref. [10] we can thus conclude that the recently derived variants of isoconversion methods [10] are highly accurate in nearly all experimental conditions. The examples discussed below should be considered as very small class of reactions where some caution should be exerted in applying isoconversion methods that use approximations of the temperature integral.

To evaluate Eq. 17 we will plot $\Delta E / E$ for a number of potentially relevant cases. In Fig. $1 \Delta E / E$ is plotted for a reaction with $T_{f 1}=350 \mathrm{~K}$ and $T_{f 2}=380 \mathrm{~K}$, with $T_{o}$ varying around $300 \mathrm{~K}$. This represents cases where the linear heating experiment is started around room temperature with a reaction occurring within $100 \mathrm{~K}$ of the start of the experiment. A start temperature between room temperature and $325 \mathrm{~K}$ is common practice in many types of studies. The relatively low reaction temperatures are commonly encountered for three types of reactions: i) GP zone or cluster formation in supersaturated $\mathrm{Al}$ based alloys $[21,22,23,24,25]$, where $\mathrm{E}$ is typically between about 50 and $80 \mathrm{~kJ} / \mathrm{mol}$; ii) dehydration reactions [26,27], where E can be substantially higher (mostly between 70 and $140 \mathrm{~kJ} / \mathrm{mol}$ ), and iii) curing reactions, where $E$ is mostly between 50 and $100 \mathrm{~kJ} / \mathrm{mol}[28,29,30]$.

a

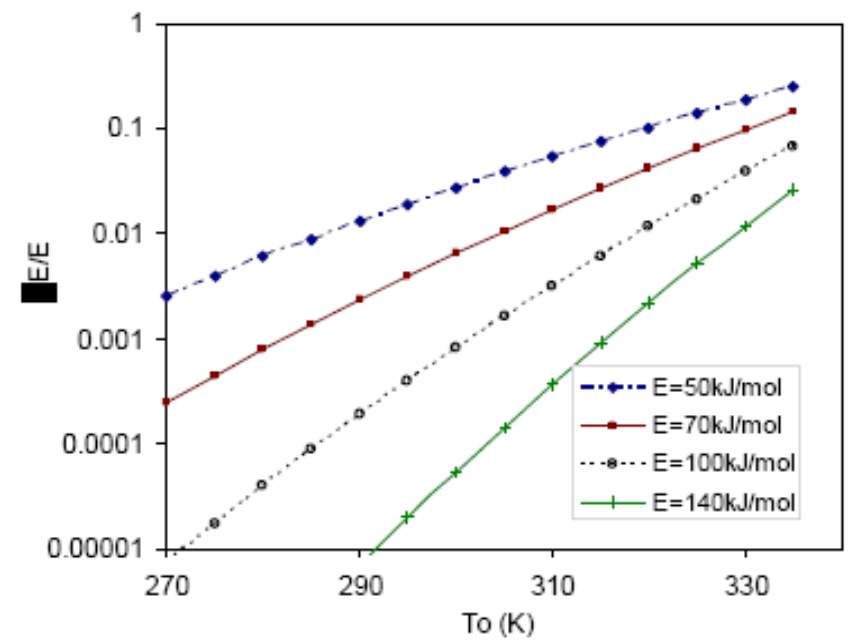

b

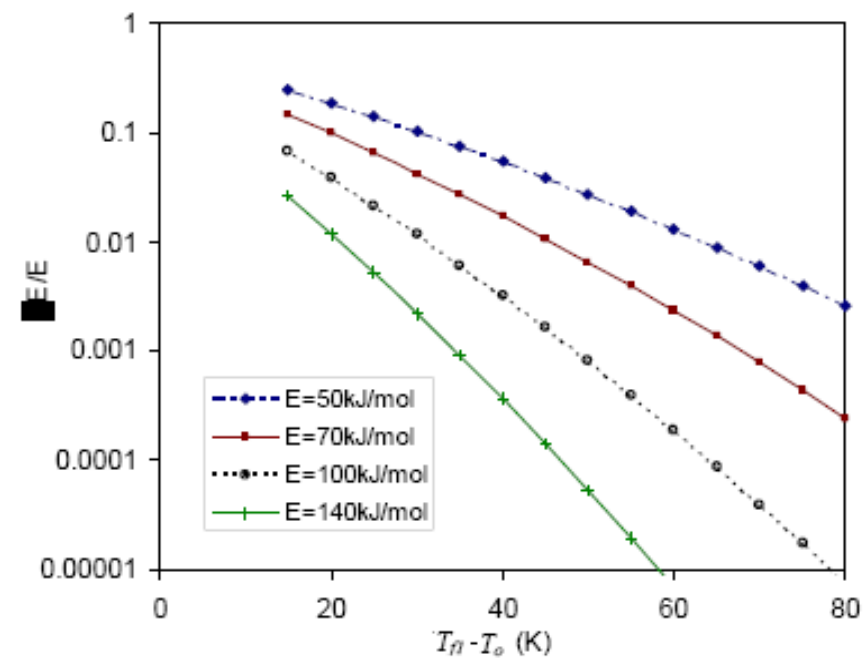

Fig. 1 The relative error in activation energy, $\Delta E / E$ vs. $T_{o}$ (a) and vs. $T_{f 1}-T_{o}$ (b) for a reaction with $T_{f l}=350 \mathrm{~K}$ and $T_{f 2}=380 \mathrm{~K}$, as obtained from Eq. 17 .

(We will consider these reactions in the next section.) Fig 1 shows that $\Delta E / E$ increases with increasing $T_{o}$ and with decreasing $E$. The same data is also plotted as a function of $T_{f I}-T_{o}$ which represents the temperature interval between the start of the linear heating experiment and the lowest temperature used for obtaining the activation energy (Fig 1b). Fig $1 \mathrm{~b}$ shows that $\Delta E / E$ decreases rapidly with increasing $T_{f 1}-T_{o}$. This is a general feature for all values of $T_{o}, T_{f 1}, T_{f 2}$ and $E$ and shows that the error introduced by 
neglecting $I\left(T_{o}\right)$ can be minimised by ensuring that the start temperature of the linear heating experiment is well below that of the reaction to be analysed.

A typical value for the relative error in activation energy determination, $\Delta E / E$, which in most experimental conditions is just about negligible is about $0.5 \%$. Fig. 2 provides a plot of the maximum allowable value of $T_{f l}-T_{o}$ for which $\Delta E / E=0.005$, as a function of the activation energy. Data for various values of $T_{f 1}$ is plotted, and $T_{f 2}-T_{f 1}=30 \mathrm{~K}$. This plot can be used as a quick reference to identify whether errors in activation energy determination are significant. It should be stressed again, that from a (limited) search through the literature it is believed that for about $99 \%$ of the papers reporting activation energy analysis using isoconversion methods on linear heating data, these errors are insignificant.

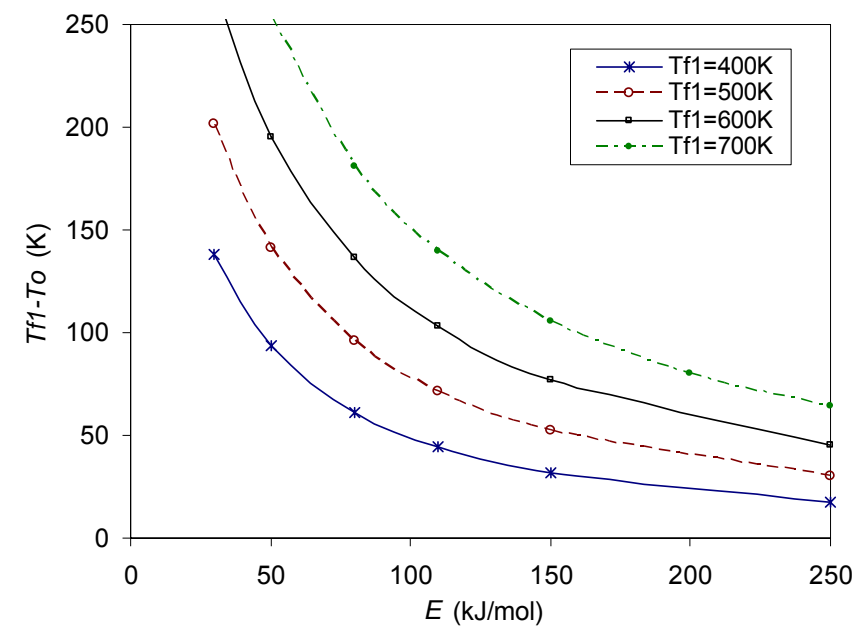

Fig. 2 The maximum allowable value of $T_{f l}-T_{o}$ for which the relative error in activation energy introduced by neglecting $I\left(T_{o}\right)$ is below $0.5 \%$, as a function of the activation energy. Data for four values of $T_{f 1}$ is plotted, $T_{f 2^{-}}$ $T_{f 1}=30 \mathrm{~K}$.

\subsection{Low temperature reactions: cluster formation, dehydration reactions, cure reactions.}

In this section we will consider some of the published data on activation energy analysis of low temperature reactions involving cluster formation, dehydration and curing. The examples are selected from recent literature and aim to provide an overview of possible deviations in activation energy analyses which assumed $I\left(T_{o}\right)$ to be negligible.

We will first consider the DSC analysis of $\mathrm{Cu}-\mathrm{Mg}$ co-cluster formation in a solution treated and quenched $\mathrm{Al}-1.9 \mathrm{Cu}-$ $1.6 \mathrm{Mg}-0.2 \mathrm{Mn}$ (at.\%) alloy [25]. The relevant parameters for this reaction $\left(T_{o}=280 \mathrm{~K}, T_{f 1}=340 \mathrm{~K}, T_{f 2}=370 \mathrm{~K}, \mathrm{E}=75 \mathrm{~kJ} / \mathrm{mol}\right.$, see Ref. [25]) indicate a $\Delta E / E$ value of $0.13 \%$, which is in practice negligible. However, it is interesting to note that if the DSC would have been started above room temperature, say $305 \mathrm{~K}$, the relative error $\Delta E / E$ in the activation energy determination would increase to $2.1 \%$ and inaccuracies would start to become significant.

Dehydration reactions often have an activation energy that is higher than that of cluster formation, and this will limit the relative error $\Delta E / E$ in the activation energy determination (see Fig 1 and Fig. 2). For instance, the dehydration reaction of hydrated $\mathrm{Co}$ (II) methanesulfonate studied by Su et al [26] the parameters $\left(T_{o}=310 \mathrm{~K}, \quad T_{f 1}=340 \mathrm{~K}, \quad T_{f 2}=370 \mathrm{~K}\right.$, $E \approx 125 \mathrm{~kJ} / \mathrm{mol}$ ) would provide $\Delta E / E$ value of $0.1 \%$, which is generally negligible. On the other hand, the dehydration reaction in 1,10-Phenanthroline studied by Vechio et al. [27] the parameters $\left(T_{o}=293 \mathrm{~K}, T_{f 1}=305 \mathrm{~K}, T_{f 2}=340 \mathrm{~K}, E \approx 85 \mathrm{~kJ} / \mathrm{mol}\right)$ would provide a $\Delta E / E$ value of about $7 \%$ for the early stage of the reaction. Thus, the activation energies quoted by Vechio et al. [27] would need to be reassessed in the light of the present findings.

Also in published analyses of cure reactions using linear heating, sometimes significant errors are introduced due to neglecting $I\left(T_{o}\right)$. Analysis shows that in the most severe cases published in Refs. [28,29,30] (most severe here means samples and analyses with lowest $T_{f 1}$ and $E$ ), $\Delta E / E$ values of $1.2 \%$ to $2.6 \%$ are encountered. But in a similar number of papers on analysis of cure reactions $\Delta E / E$ values are always below $1 \%$.

\subsection{Multi-stage reactions with reversion stage.}

In addition to the reactions where the start temperature of the linear heating experiment is just below the reaction to be studied, we may also consider cases where the effective $T_{o}$ for a reaction is defined by prior reactions. This could be the case where during heating a sequence of reactions occurs starting with the formation of a phase or structure stable at low temperature, here termed $\delta^{\prime}$, which is stable only below a certain temperature $T_{S}$, and which is followed by the formation of the stable phase or structure, here symbolised by $\delta$. If the original unstable state at the start of the linear heating is $\alpha$, and the three states are the only ones possible, then we could either see the sequence of reaction on heating (reaction $\mathrm{A})$ :

$$
\alpha \rightarrow \delta^{\prime} \rightarrow \delta
$$


Or if on passing $T_{S} \delta^{\prime}$ reverts to $\alpha$ (reaction B)

$$
\alpha \rightarrow \delta^{\prime} \rightarrow \alpha \rightarrow \delta
$$

(Also, under fast heating rate condition one could see $\alpha \rightarrow \delta$ )

In reaction $\mathrm{B}$, any formation of $\delta^{\prime}$ can only occur after $\delta^{\prime}$ has dissolved, and hence we can think of $T_{S}$ as the effective start temperature of the linear heating experiment analysing $\delta$ formation. Hence we can consider $T_{o}$ to be given by $T_{S}$. There are many reactions in the domains of chemistry, physics and materials science that could be influenced by this, and hence influence the activation energy analysis. Again this can be analysed by Eq. 17, with $T_{S}$ substituted for $T_{o}$. Here we will illustrate this by considering precipitation reactions in $\mathrm{Al}$ based alloys.

In Al-Mg based alloys, two main precipitate structures are formed on isothermal ageing below about $360 \mathrm{~K}$ and subsequent linear heating to about $310 \mathrm{C}$, they are the low temperature $\mathrm{L}_{2}$ ordered precipitates generally indicated by $\beta^{\prime \prime}$ (other indications: $\delta^{\prime}$, ordered GP zone) [31,32,33] and the $\beta^{\prime}$ phase, which forms at higher temperatures (typically $\mathrm{T}>450 \mathrm{~K})$ [34]. In Fig 2 we can observe the $\beta^{\prime \prime}$ dissolution reaction in room temperature aged samples; for samples aged very long times at room temperature this reaction is completed at about $110 \mathrm{C}$, with the $\beta^{\prime}$ phase formation starting at about $220 \mathrm{C}$. With an activation energy for $\beta^{\prime}$ formation of about $75 \mathrm{~kJ} / \mathrm{mol}$ [31], Eq. 17 indicates that $\Delta E / E$ is smaller than $0.3 \%$, and hence neglecting of $I\left(T_{o}\right)$ could not have influenced the determination of the activation energy significantly.

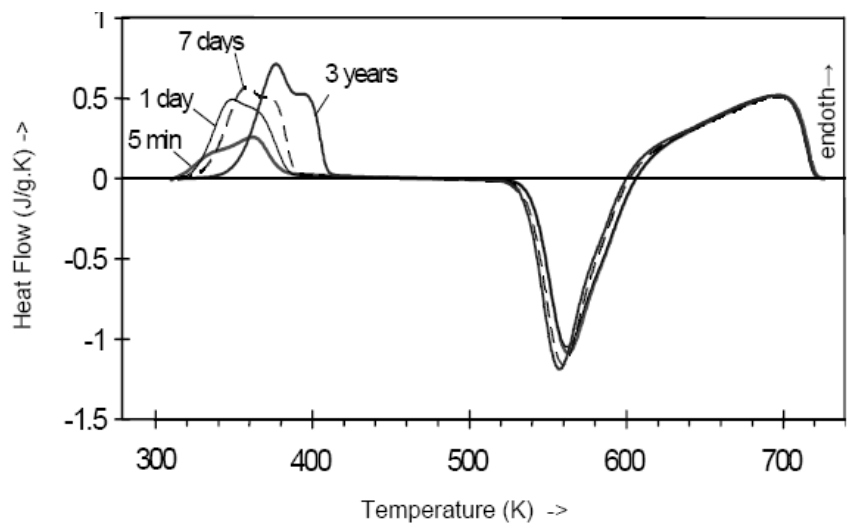

Fig. 3 DSC curves of ice water quenched Al-16Mg samples aged for $5 \mathrm{~min}, 24 \mathrm{~h}, 7$ days and 3 years at room temperature after solutionising at 713K. (From Ref [32])
In solution treated $\mathrm{Al}-\mathrm{Cu}-\mathrm{Mg}$ based alloys with compositions in the $\alpha+\mathrm{S}$ phase field (at around $500 \mathrm{~K}$ ), linear heating will cause the formation $\mathrm{Cu}-\mathrm{Mg}$ co-clusters (also termed GPB zones) $[35,36,37,38]$ and $\mathrm{S}$ phase $[39,40,41]$. If the alloys are aged at low temperature to cause the formation of $\mathrm{Cu}-\mathrm{Mg}$ coclusters, subsequent linear heating will cause the reversion of clusters prior to formation of $\mathrm{S}$ phase. Estimating $T_{o}$ as the effective temperature for cluster dissolution $(230 \mathrm{C})$ and $T_{f}$ at the peak of $\mathrm{S}$ phase formation, the relevant parameters for this reaction $\left(T_{o}=500 \mathrm{~K}, T_{f 1}=530 \mathrm{~K}, T_{f 2}=545 \mathrm{~K}, E \approx 130 \mathrm{~kJ} / \mathrm{mol}\right.$, see Ref. [1,22] and Fig. 4) indicate a $\Delta E / E$ value of $\sim 8 \%$. Thus, the activation energies for $\mathrm{S}$ phase formation obtained by linear heating would need to be considered with caution as they may be influenced by neglecting $I\left(T_{o}\right)$.

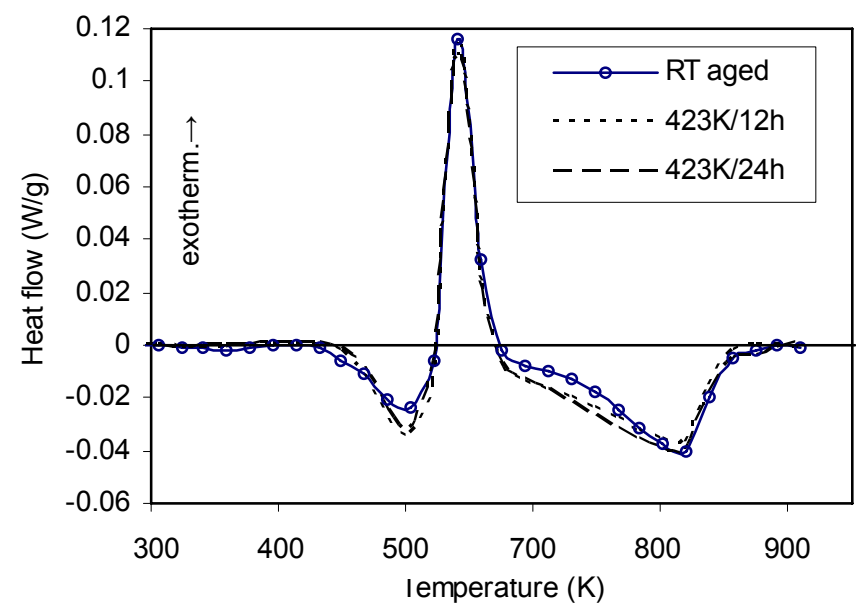

Fig. 4 DSC curves of samples of an Al-1.21 at $\% \mathrm{Cu}-$ $1.19 \mathrm{at} \% \mathrm{Mg}-0.20 \mathrm{at} \% \mathrm{Mn}$ alloy solution treated, quenched, stretched by $2.5 \%$, room temperature aged for several months and (for two of the samples) aged at $423 \mathrm{~K}$.

5

\section{Conclusions}

Model-free isoconversion methods which use approximations of the temperature integral are generally reliable methods for the calculation of activation energies, $E$, of thermally activated reactions studied during linear heating. These methods generally neglect the temperature integral at the start of the linear heating, $I\left(T_{o}\right)$. In the present work an analytical equation is derived which describes the deviations introduced by neglecting $I\left(T_{o}\right)$. The $\Delta E$ is a function of $T_{o}, T_{f 1}, T_{f 2}$ and $E$, where the $T_{f 1}, T_{f 2}$ are the temperatures of a fixed stage of the reaction achieved at heating rates $\beta_{1}, \beta_{2}$, respectively. Evaluation of this equation shows: 
- For most reactions encountered, neglecting $I\left(T_{o}\right)$ does not have a significant influence on the accuracy of the isoconversion method. Plots are presented which show the deviations introduced as a function of $T_{o}, T_{f 1}, T_{f 2}$ and E.

- In cases where $T_{o}$ is within about 50 to $70 \mathrm{~K}$ of the reaction stage to be investigated and activation energies are relatively low, significant deviations can be introduced.

- It is shown that some of the published thermal analysis work on activation energy analysis of reaction occurring at relatively low temperatures is affected. Examples are specific cases of dehydration reactions, cure reactions and cluster formation in $\mathrm{Al}$ alloys.

Acknowledgements Dr Nong Gao is gratefully acknowledged for performing DSC experiments presented in Fig 4.

\section{References}

$1 \quad$ M.J. Starink, Int. Mater. Rev. 49 (2004) 191

2 A.K. Galwey and M.E. Brown, in: M.E. Brown (Ed.), Handbook of Thermal Analysis and Calorimetry, Vol. 1, Elsevier, Amsterdam, 1998, p. 147

3 F. Liu, F. Sommer and E.J. Mittemeijer, J. Mater. Sci. 39 (2004) 1621

$4 \quad$ M.J. Starink and A.-M. Zahra, Phil. Mag. A 77 (1998) 187

5 S. Vyazovkin, Thermochim. Acta 355 (2000) 155

6 M.J. Starink and A.-M. Zahra, Thermochim. Acta 298 (1997) 298

7 J.H. Flynn, Thermochim. Acta 300 (1997) 83

8 J. D. Sewry and M. E. Brown, Thermochim. Acta 390 (2002) 217

9 Tang Wanjun and Chen Donghua, Thermochim. Acta 433 (2005) 72

10 M.J. Starink, Thermochim. Acta 404 (2003) 163

11 H. E. Kissinger, Analyt. Chem. 29 (1957) 1702

12 T. Ozawa, J. Therm. Anal. 2 (1970) 301

13 E.J. Mittemeijer, J. Mater. Sci. 27 (1992) 3977

14 J.H. Flynn and L.A. Wall, J Polym Sci Part B 4 (1966) 323

15 T. Ozawa, Thermochim. Acta 203 (1992) 159

16 S. Vyazovkin and V.V. Goriyachko, Thermochim. Acta 194 (1992) 221

17 S. Vyazovkin and A.I. Lesnikovich, Russ. J. Phys. Chem. 62 (1988) 2949

18 M.J. Starink, Thermochim. Acta 288 (1996) 97

19 M.J. Starink, J. Mater. Sci. 32 (1997) 6505

20 M.J. Starink, I. Sinclair, N. Gao, N. Kamp, P.J. Gregson, P. Pitcher, A. Levers and S. Gardiner, Mater. Sci. Forum 396402 (2002) 601

21 M.J. Starink, N. Gao, J.L. Yan, Mater. Sci. Eng. A 387-389 (2004) 222

22 A. Charai, T. Walther, C. Alfonso, A.-M. Zahra and C. Y. Zahra, Acta Mater. 48 (2000) 2751
23 M.J. Starink and A.-M. Zahra, J. Mater. Sci. Lett. 16 (1997) 1613

24 S. Abis, M. Massazza, P. Mengucci and G. Riontino, Scr. Mater. 45 (2001) 685

25 M.J. Starink, N. Gao, L. Davin, J. Yan, A. Cerezo, Phil. Mag. 85 (2005) 1395

26 Ting-Ting Su, Heng Jiang and Hong Gong, Thermochim. Acta 435 (2005) 1

27 S. Vecchio, R. Di Rocco, C. Ferragina and S. Materazzi, Thermochim. Acta 35 (2005) 181

28 I. Mondragon, L. Solar, I.B. Recalde and C.M. Gómez, Thermochim. Acta 417 (2004) 19

29 Tianle Zhou, Mingyuan Gu, Yanping Jin and Junxiang Wang, Polymer 46 (2005) 6216

30 Guangbo He and Ning Yan, Int. J. Adhesion and Adhesives 25 (2005) 450

31 M.J. Starink and A.-M. Zahra, Acta Mater. 46 (1998) 3381

32 M.J. Starink and A.-M. Zahra, Phil. Mag. A 76 (1997) 701

33 M. Slabanja and G. Wahnström, Acta Mater. 53 (2005) 3721

34 M.J. Starink and A.-M. Zahra, J. Mater. Sci. 34 (1999) 1117

35 N. Gao, L. Davin, S. Wang, A. Cerezo and M.J. Starink, Mater. Sci. Forum, 396-402 (2002) 923

36 K. Hono, Prog. Mater. Sci. 47 (2002) 621

37 S.C. Wang and M.J. Starink, Mater. Sci. Eng. A 386 (2004) 156

38 M.J. Starink, C.Y. Zahra and A.-M. Zahra, J. Therm. Anal. and Calorim. 51 (1998) 933

39 M.J. Starink and A. Dion, Thermochim. Acta 417 (2004) 5

40 S.C. Wang and M.J. Starink, Int. Mater. Rev. 50 (2005) 193

41 S.C. Wang, M.J. Starink and N. Gao, Scr. Mater. 54 (2006) 287 